\title{
Dynamics of staphylococcal enterotoxin production in model experiments simulating the fresh cheese environment
}

\author{
Lenka Necidová ${ }^{1}$, Bohdana Janštová1, Renáta Karpíškováa ${ }^{1,2}$ \\ ${ }^{1}$ University of Veterinary and Pharmaceutical Sciences Brno, Faculty of Veterinary Hygiene \\ and Ecology, Department of Milk Hygiene and Technology, Brno, Czech Republic \\ ${ }^{2}$ National Institute of Public Health Prague, Brno, Czech Republic
}

Received March 15, 2012

Accepted August 13, 2012

\begin{abstract}
The aim of this study was to evaluate the impact of internal factors $(\mathrm{pH}, \mathrm{NaCl})$ and external factors (temperature, incubation time) on the ability of Staphylococcus aureus to grow and to produce staphylococcal enterotoxins SEA, SEB, and SEC. The fresh cheese environment was modelled in Brain Heart Infusion Broth media and food matrices (pasteurized milk from retail outlets) by internal and external factors $\left(\mathrm{pH}=4.5\right.$ and $5.5,2 \% \mathrm{NaCl}$, and $\mathrm{t}=8{ }^{\circ} \mathrm{C}$ and $15{ }^{\circ} \mathrm{C}$ ). The counts of enterotoxigenic strains of $S$. aureus at baseline, i.e. at the time of inoculation of model samples, corresponded to those encountered in the production of fresh cheeses as a result of post-pasteurization contamination. Enumeration of $S$. aureus was performed in accordance with EN ISO 6888-1, using agar medium. Staphylococcal enterotoxins were detected by the enzyme-linked fluorescence assay. The $\mathrm{pH}(4.5)$ and refrigeration temperature $\left(8^{\circ} \mathrm{C}\right)$ used prevented $S$. aureus from achieving the critical count of $10^{5} \mathrm{cfu} \cdot \mathrm{ml}^{-1}$ specified in Commission Regulation (EC) No. 2073/2005. The highest rates of enterotoxin production were recorded for enterotoxin A. The growth curves of $S$. aureus derived from model experiments were compared with the growth curve generated by a predictive microbiology program - Pathogen Modelling Program. The results of this study proved the Pathogen Modelling Program to be suitable for use in the Hazard Analysis Critical Control Points system in the process of the fresh cheese production to help manufacturers prevent the growth of $S$. aureus and enterotoxin production.
\end{abstract}

Staphylococcus aureus, ELFA, miniVIDAS ${ }^{\circledR}$, Pathogen Modelling Program, food safety

Staphylococcus aureus is an important food-borne pathogen involved in a variety of invasive diseases. From the perspective of food microbiology, a crucial factor is the ability of certain $S$. aureus strains to produce heat stable enterotoxins that can cause staphylococcal food poisoning and are a leading cause of gastroenteritis worldwide (Scherrer et al. 2004). The symptoms of staphylococcal food poisoning are abdominal cramps, nausea, vomiting, sometimes followed by diarrhoea (never diarrhoea alone). The onset of symptoms is rapid (from $30 \mathrm{~min}$ to $8 \mathrm{~h}$ after ingestion), and symptoms usually subside within $24 \mathrm{~h}$ (Loir et al. 2003).

Raw milk hygienic and health safety indicators including total bacteria count and occurrence of pathogenic microorganisms have to be assessed for objective estimation of milk quality; it is necessary to reliably detect causative agents of human alimentary diseases (Hubackova and Rysanek 2007). S. aureus is the major causative agent of mastitis in cows (Rabello et al. 2007) and have been detected in milk and milk products (Morandi et al. 2009; Ertas et al. 2010). Skin microflora on workers' hands can be a secondary bacteria food contaminant (Sattar et al. 2001). During the production, storage, and distribution of milk and dairy products, bacteria can proliferate and subsequently produce staphylococcal enterotoxins (SEs). While staphylococci can be destroyed easily, enterotoxins can survive practically all food processing.

From the point of view of food-borne disease risk it is a concern that $50-75 \%$ of $S$.

Address for correspondence:

MVDr. Lenka Necidová, Ph.D.

Department of Milk Hygiene and Technology,

Faculty of Veterinary Hygiene and Ecology,

University of Veterinary and Pharmaceutical Sciences Brno

Palackého tř. 1/3, 61242 Brno, Czech Republic 
aureus strains can produce, under suitable conditions, heat stable extracellular enterotoxins (Morandi et al. 2009). Twenty types of currently recognized staphylococcal enterotoxins designated by letters from A to U (Ono et al. 2008). The classical SEs responsible for staphylococcal food poisoning are SEA, SEB, SEC1, SEC2, SEC3, SED, SEE, and some new enterotoxins.

$S$. aureus counts in food with a range as low as $10^{3}$ to $10^{5} \mathrm{cfu} \cdot \mathrm{g}^{-1}$ can produce the amount of toxin that poses a risk to consumers (J ablonski and Bohach 2001). An enterotoxin dose of less than 1.0 microgram in contaminated food can produce symptoms of staphylococcal intoxication. This toxin level is reached when $S$. aureus populations exceed $10^{5} \mathrm{cfu} \cdot \mathrm{g}^{-1}$. This is also the value determined by current legislation as hazardous (Commission Regulation (EC) No. 2073/2005).

Our study monitored the growth characteristics of seven $S$. aureus strains and their potential to produce enterotoxins, in both a culture medium and in a model food matrix simulating the fresh cheese environment. Our findings can help cheese producers to adopt effective measures to prevent $S$. aureus growth and enterotoxin production during the production process.

\section{Materials and Methods}

\section{Samples}

In the model experiments, Brain Heart Infusion (BHI) broth (HiMedia, India) and food matrix (pasteurized cow's milk) were inoculated with seven $S$. aureus strains. They originated from milk and dairy products and were kept in the collection of microorganisms of the National Institute of Public Health, Prague, Department of Nutrition and Food Safety, Brno, Czech Republic. All seven strains were producers of enterotoxins of types A, B, or C (1515-A, 1665-A, 1666-A, 1106-B, 1057-B, 1735-B, and 1168-C). All strains showed typical growth on Baird-Parker agar (Oxoid, UK). The ability of the strains to produce enterotoxins was tested by the reverse passive latex agglutination method (Denka Seiken Co., Ltd., Japan) according to the manufacturer's instructions.

Our first model BHI broth samples were inoculated with strains A, B, and C (HiMedia) at a concentration range of $1.7 \times 10^{2}-2.0 \times 10^{4} \mathrm{cfu} \cdot \mathrm{ml}^{-1}$. The following internal and external factors in BHI broth were used to simulate a fresh cheese environment: $\mathrm{pH}=4.5$ and $5.5,2 \% \mathrm{NaCl}(\mathrm{w} / \mathrm{v}), \mathrm{t}=8^{\circ} \mathrm{C}$ and $15^{\circ} \mathrm{C}$. Sampling was performed once daily for 22 days and the mean bacterial counts were calculated.

Our second model study focused on the production of staphylococcal enterotoxins SEA and SEB under the following conditions: $\mathrm{pH}=5.5,2 \% \mathrm{NaCl}(\mathrm{w} / \mathrm{v})$, and $\mathrm{t}=15^{\circ} \mathrm{C}$. The $\mathrm{BHI}$ broth and a food matrix (retail pasteurized milk) were inoculated with $S$. aureus at a concentration range of $6.4 \times 10^{1}-1.3 \times 10^{3} \mathrm{cfu} \cdot \mathrm{ml}^{-1}$ for culture. A 3-h sampling interval was used for testing the production of SEA and SEB. The enumeration of $S$. aureus was done at a 12-h interval, and the mean bacterial counts were calculated from the results of both parallel and repeated experiments.

\section{Quantitative detection of $S$. aureus}

Each sample was examined and coagulase-positive staphylococci were enumerated according to ČSN EN ISO 6888-1 by the technique using Baird-Parker agar medium (Oxoid, UK). The identification of typical colonies was based on the growth on blood agar and the results of coagulase tests Staphylo LA Seiken (Denka Seiken Co., Ltd., Japan) and Dry Spot Staphytect Plus (Oxoid, UK).

Detection of staphylococcal enterotoxins

Staphylococcal enterotoxins were detected by the Enzyme-Linked Fluorescence Assay (ELFA) using a MiniVIDAS $^{\circledR}$ analyzer (Vitek Immuno Diagnostic Assay System, bioMérieux, France) which is able to detect the sum of enterotoxins SEA-SEE with the detection limits of $0.5 \mathrm{ng} / \mathrm{g}$ or per $\mathrm{ml}$ of food for SEA and SEB and of 1.0 $\mathrm{ng} / \mathrm{g}$ or per $\mathrm{ml}$ of food for SEC-SEE.

The samples were processed according to the manufacturer's instructions as follows: $\mathrm{pH}$ was adjusted to range from 3.5 to 4 , the supernatant was obtained by centrifugation, and its $\mathrm{pH}$ was adjusted to $7.5-8$. The final sample yielded after additional centrifugation was transferred directly to the well of the VIDAS SET2 strip. As the ELFA technique does not allow the quantitative detection of SEs, the results are expressed as either positive or negative based on Relative Fluorescence Values (RFVs).

Comparison with the Pathogen Modeling Program (PMP) online outcomes

The growth rates of the staphylococcal strains tested were compared with the predicted growth curves generated using predictive microbiology software, the Pathogen Modeling Program (PMP) Online (USDA-ARS, USA). 


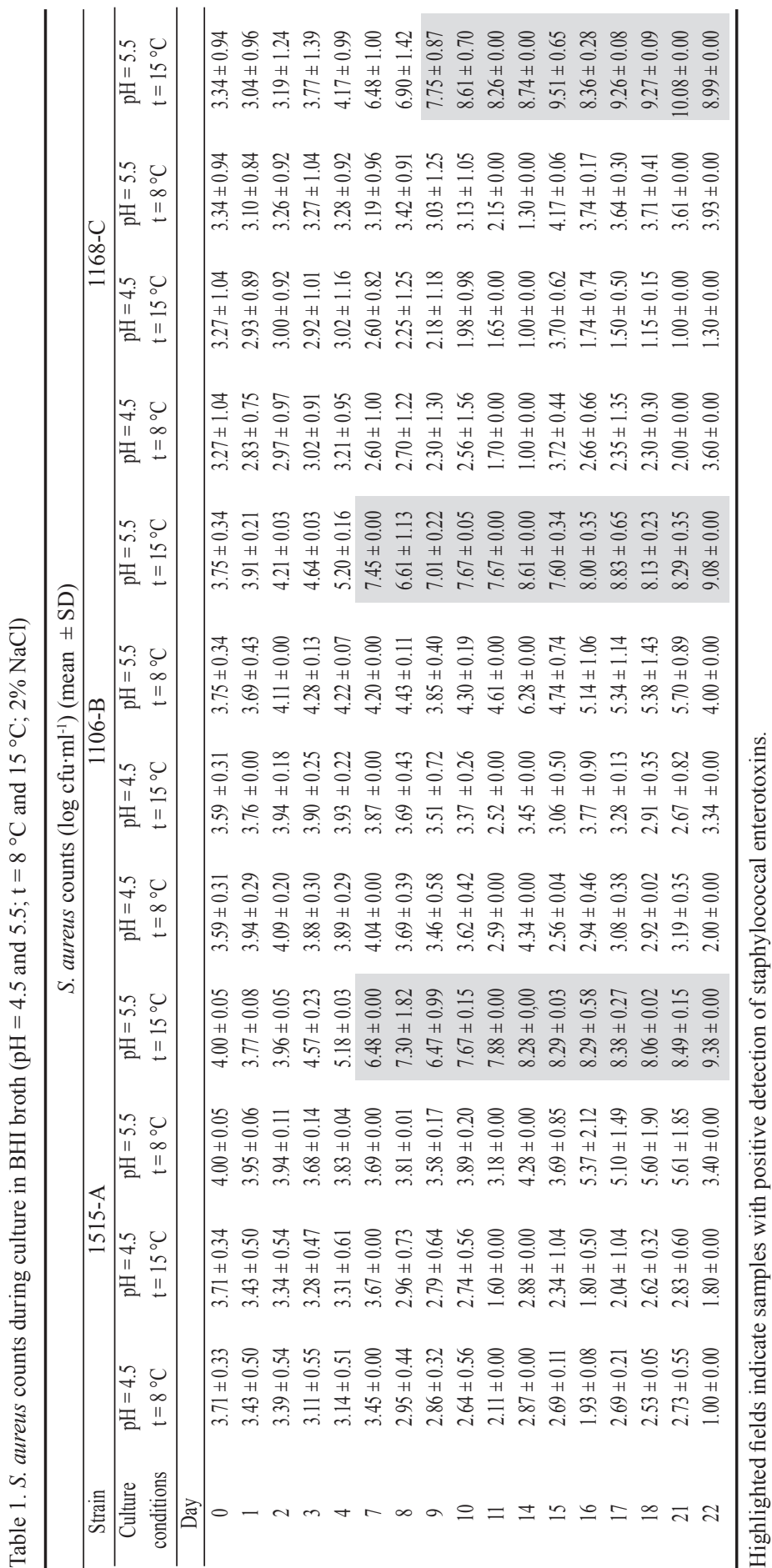

\section{Results}

Our first model experiment focused on the growth of three $S$. aureus strains (1515-A, 1106-B, and 1168-C) and their production of enterotoxins. These strains were incubated in BHI broth for 22 days, with external and internal factors simulating the fresh cheese environment. Table 1 presents $S$. aureus counts from repeated experiments determined in $\mathrm{BHI}$ with $2 \% \quad \mathrm{NaCl}$ at a $\mathrm{pH}$ of 4.5 and 5.5 and at $8{ }^{\circ} \mathrm{C}$ (i.e. the maximum temperature limit for storage, transport, and retail display of fresh cheeses pursuant to Regulation No. 124/2004), and $15^{\circ} \mathrm{C}$ (i.e. the temperature of mild refrigeration or a broken cold chain). All three strains produced SEs exclusively with a $\mathrm{pH}=5.5$ and $15^{\circ} \mathrm{C}$ environment. SEA and SEB were first detected on the $7^{\text {th }}$ day, SEC on the $9^{\text {th }}$ day.

The second model experiment was a more detailed study of SEA production (Figs 1a-c) and SEB (Figs 2a-c) in an environment with $2 \% \mathrm{NaCl}$ at a $\mathrm{pH}$ of 
5.5 and $15^{\circ} \mathrm{C}$. As seen with Figs 1a-c, SEA production was first detected in all three strains (1515-A, 1665-A, and 1666-A) in BHI broth between 111-144 hours (from day 5 to 6) and in 1515-A strain only in milk between 111 to $120 \mathrm{~h}$ (on day 5). No enterotoxin production was detected in strains 1665-A and 1666-A during the entire period of incubation, i.e. over an 8-day period. Figs 2a-c show that SEB production was not detected either in milk or in

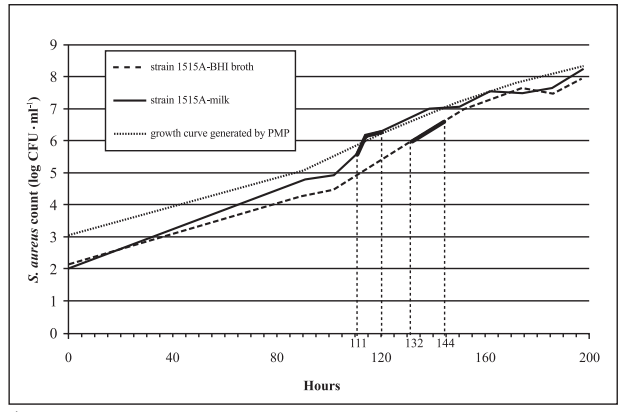

$1 \mathrm{a}$

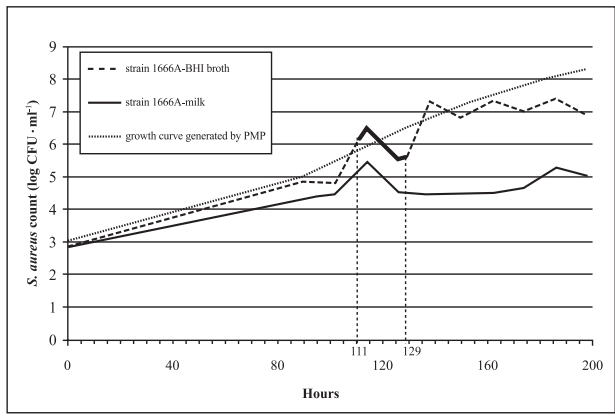

$1 c$

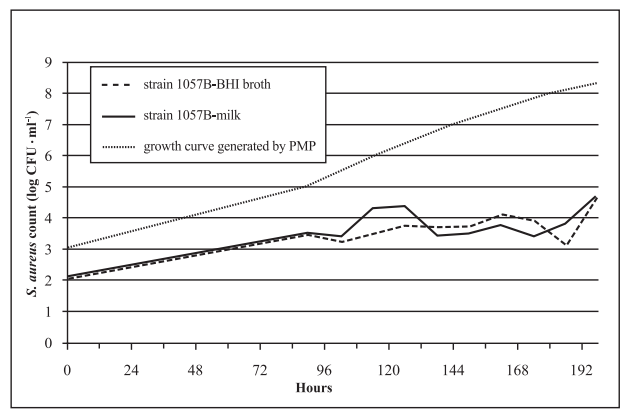

$2 b$

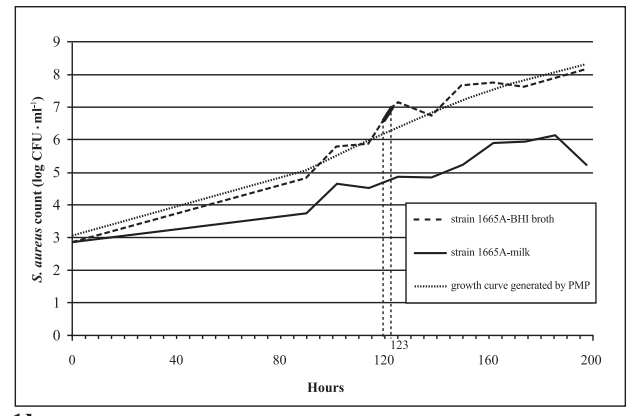

$1 b$

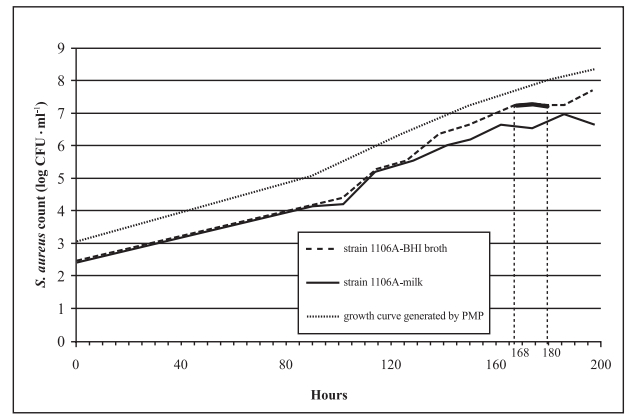

2a

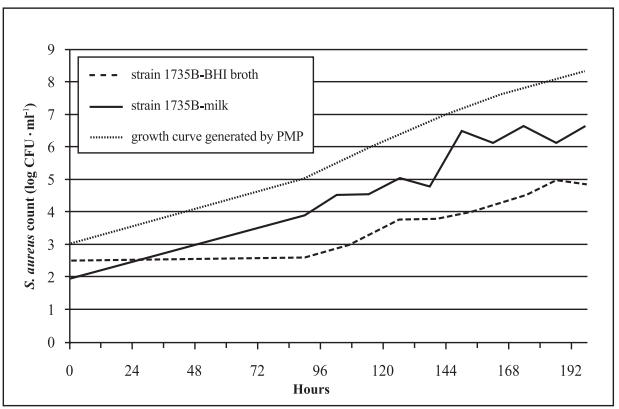

2c

Fig. 1. Growth curve of $S$. aureus strains 1515-A (1a), 1665-A (1b), 1666-A (1c) and first detection interval of SEA in BHI broth and milk $\left(\mathrm{pH}=5.5 ; \mathrm{t}=15^{\circ} \mathrm{C} ; 2 \% \mathrm{NaCl}\right)$

Fig. 2. Growth curve of $S$. aureus strains 1106-B (2a), 1057-B (2b), 1735-B (2c) and first detection interval of $\mathrm{SEB}$ in BHI broth and milk $\left(\mathrm{pH}=5.5 ; \mathrm{t}=15^{\circ} \mathrm{C} ; 2 \% \mathrm{NaCl}\right)$ 
BHI broth during the entire period of incubation, with the exception of strain 1106-B which produced enterotoxin in BHI broth between 168-180 h (on days 7 and 8).

\section{Discussion}

Results of our model experiments studying $S$. aureus growth and enterotoxin production showed that fresh cheeses pose potential health risk. SE-positive $S$. aureus isolates from cheeses are most often producers of SEA, SEB, or SEC. Some of $S$. aureus isolates from goat's milk cheese were enterotoxinogenic and produced SEA or SEC (Akineden et al. 2008). Ertas et al. (2010) found the sea $(1.3 \%)$, seb (0.6\%) and sed (0.3\%) genes in isolates from sheep's milk cheese. As seen in Table 1, higher $S$. aureus counts and enterotoxin production were only detected at a $\mathrm{pH}$ of 5.5 and at $15^{\circ} \mathrm{C}$. Enterotoxin production was first detected in all strains on day 7-9 at counts of $\log 6.48 \pm 0.00-\log 7.75 \pm 0.87 \mathrm{cfu} \cdot \mathrm{ml}^{-1}$. This study showed that the growth of $S$. aureus was clearly inhibited at $8{ }^{\circ} \mathrm{C}$ or at a $\mathrm{pH}$ of 4.5. Although at $8^{\circ} \mathrm{C}$ with a $\mathrm{pH}$ of 5.5, SEA and SEB producing strains reached higher counts than $10^{5} \mathrm{cfu} \cdot \mathrm{ml}^{-1}$ from days 14 and 16 , and enterotoxin production was not detected.

In general, $S$. aureus grows between 7 and $48{ }^{\circ} \mathrm{C}$, with an optimum of $35-40{ }^{\circ} \mathrm{C}$, $\mathrm{pH}$ between 4-10, with an optimum of 6-7, and sodium chloride with concentrations up to $25 \%$. Enterotoxins are produced between 10 and $46{ }^{\circ} \mathrm{C}$, with an optimum of $35-45{ }^{\circ} \mathrm{C}$. Enterotoxin production is unlikely to occur at temperatures below $10{ }^{\circ} \mathrm{C}$. Optimum enterotoxin production occurs at a $\mathrm{pH}$ of 6-7 and the minimum $\mathrm{pH}$ suitable is about 4.8. At temperatures below $8{ }^{\circ} \mathrm{C}$, the growth of $S$. aureus was inhibited, with no growth observed at $7.5{ }^{\circ} \mathrm{C}$ and at $8{ }^{\circ} \mathrm{C}$, growth only occurred with optimum levels of $\mathrm{pH}$ and $\mathrm{a}_{\mathrm{w}}$ (Valero et al. 2009). Staphylococcal counts should reach approximately $10^{6} \mathrm{cfu} \cdot \mathrm{g}^{-1}$ to be associated with enterotoxin production (Necidova et al. 2009). It is possible for $S$. aureus to grow slowly at a refrigeration temperature without producing enterotoxin (Roberts et al. 1996).

Mainly compliance with good hygienic practices that avoid post-pasteurization milk contamination, lowering the $\mathrm{pH}$ level (4.5) and maintaining refrigeration temperature at a maximum of $8^{\circ} \mathrm{C}$ can prevent $S$. aureus from reaching the critical count of $10^{5} \mathrm{cfu} \cdot \mathrm{ml}^{-1}$ specified by Commission Regulation (EC) No. 2073/2005.

In most strains, the absence of SEs production was associated with a low count of $S$. aureus (Table 1, Figs 1a-c,2a-c). The count was often below the limit for the production of enterotoxins, although Jablonski and Bohach (2001) have reported that $S$. aureus counts as low as $10^{3}$ to $10^{5} \mathrm{cfu} \cdot \mathrm{g}^{-1}$ of food can produce the amount of toxin that poses a risk to consumers. The production of enterotoxins SEA and SEB was only detected in both BHI broth and milk when the count of $S$. aureus exceeded the critical level of $10^{5} \mathrm{cfu} \cdot \mathrm{ml}^{-1}$.

Figs 1a-c, 2a-c show the growth curve generated using the Pathogen Modelling Program (PMP) online (USDA-ARS, USA) for $S$. aureus cultured aerobically at $15^{\circ} \mathrm{C}$, $\mathrm{pH}$ of $5.5,2.1 \% \mathrm{NaCl}$, and baseline bacterial count of $10^{3} \mathrm{cfu} \cdot \mathrm{ml}^{-1}$. This program is based on experimental results obtained in culture media such as Brain Heart Infusion Broth (Buchanan et al. 1993) and should predict the characteristics of bacterial growth in food. Several kinetic predictive growth models of $S$. aureus can be found in related literature (Sutherland et al. 1994; Zurera-Cosano et al. 2004).

The results of our present study verified that the rates of $S$. aureus growth, and in particular of its production of SEs in BHI broth and milk, varied. Higher S. aureus counts and higher enterotoxin production were more often seen in the growth medium than in the food matrix. Moreover, it is evident that the higher rate of SEA production is a characteristic feature of this type of enterotoxin. None of the real growth curves crossed the high-risk limit for SEs production $\left(10^{5} \mathrm{cfu} \cdot \mathrm{ml}^{-1}\right)$ earlier than the predicted curves generated by the PMP software. This supports the suitability for use of PMP software with Critical Control 
Points (HACCP) systems in the process of fresh cheese production. Therefore, PMP can be successfully used as a part of the HACCP system for staphylococcal food poisoning prevention during the production of fresh cheeses, reducing risk as much as possible.

\section{Acknowledgements}

This work was conducted with the support of MSM Project no. 6215712402 Veterinary Aspects of Food Safety and Quality and IGA 18/2012/FVHE.

\section{References}

Akineden Ö, Hassan AA, Schneider E, Usleber E 2008: Enterotoxigenic properties of Staphylococcus aureus isolates from goats' milk cheese. Int J Food Microbiol 124: 211-216

Buchanan RL, Smith JL, McColgan C, Marmer BS, Golden MH, Dell BJ 1993: Response surface models for the effects of temperature, $\mathrm{pH}$, sodium chloride and sodium nitrite on the aerobic and anaerobic growth of Staphylococcus aureus 196E. J Food Safety 13: 159-175

EC No. 2073/2005: Commission Regulation (EC) No. 2073/2005 on microbiological criteria for foodstuffs. OJEU, L 322/12

Ertas N, Gonulalan Z, Yildirim Y, Kum E 2010: Detection of Staphylococcus aureus enetrotoxins in wheel cheese and dairy dessserts by multiplex PCR technique. Int J Food Microbiol 142: 74-77

Hubackova M, Rysanek D 2007: Effects of freezing milk samples on the recovery of alimentary pathogens and indicator microorganisms. Acta Vet Brno 76: 301-307

Jablonski LM, Bohach G 2001: Staphylococcus aureus. In: Doyle MP, Beuchat LR, Montville TJ (Ed.): Food microbiology: Fundamentals and Frontiers. ASM Press, Washington, pp. 411-434

Loir Y, Baron F, Gautier M 2003: Staphylococcus aureus and food poisoning. Genet Mol Res 2: 63-76

Morandi S, Brasca M, Andrighetto C, Lombardi A, Lodi R 2009: Phenotypic and genotypic characterization of Staphylococcus aureus strains from Italian dairy products. Int J Microbiol 2009: $7 \mathrm{p}$.

Necidova L, Stastkova Z, Pospisilova M, Janstova B, Strejcek J, Duskova M, Karpiskova R. 2009: Influence of soft cheese technology on the growth and enterotoxin production of Staphylococccus aureus. Czech J Food Sci 27: 127-133

Ono HK, Omoe K, Imanishi K, Iwakabe Y, Hu DL, Kato H, Saito N, Nakane A, Uchiyama T, Shinagawa K 2008: Identification and characterization of two novel staphylococcal enetrotoxins, types $\mathrm{S}$ and $\mathrm{T}$. Infect Immun 76: 4999-5005

Rabello RF, Moreira BM, Lopes RM, Teixeira LM, Riley LW, Castro AC 2007: Multilocus sequence typing of Staphylococcus aureus isolates recovered from cows with mastitis in Brazilian dairy herds. J Med Microbiol 56: $1505-1511$

Regulation No 124/2004 of the Ministry of Agriculture amending Regulation No 77/2003 laying down the requirements for milk and dairy products, ice creams, and edible fats and oils.

Roberts TA, Baird-Parker AC, Tompkin RB 1996: Microorganisms in Food 5: Characteristics of microbial pathogens. Blackie Academic and Professional, London, pp. 299-333

Sattar SA, Springthorpe S, Mani S, Gallant M, Nair RC, Scott E, Kain J 2001: Transfer of bacteria from fabrics to hands and other fabrics: development and application of a quantitative method using Staphylococcus aureus as a model. J Appl Microbiol 90: 962-970

Scherrer D, Corti S, Muehlherr JE, Zweifel C, Stephan R 2004: Phenotypic and genotypic characteristics of Staphylococcus aureus isolates from raw bulk-tank milk samples of goats and sheep. Vet Microbiol 101: $101-107$

Sutherland JP, Bayliss AJ, Roberts TA 1994: Predictive modeling of growth of Staphylococcus aureus: the effects of temperature, $\mathrm{pH}$ and sodium chloride. Int J Food Microbiol 21: 217-236

United States Department of Agriculture, Agricultural Research Service Department of AgricultureAgricultural Research Service (USDA-ARS), Eastern Regional Research Center (ERRC) in Wyndmoor, Pennsylvania. Pathogen Modeling Program (PMP) Online. Available at: www.pmp.arserrc.gov/PMPOnline. aspx?ModelID=4\&Aerobic=True. Last modified July 17, 2012. Accessed April 5, 2012

Valero A, Pérez-Rodriguez F, Carrasco E, Fuentes-Alventosa JM, García-Gimeno RM, Zurera G 2009: Modelling the growth boundaries of Staphylococcus aureus: Effect of temperature, $\mathrm{pH}$ and water activity. Int J Food Microbiol 133: 186-194

Zurera-Cosano G, Castillejo-Rodriguez AM, García-Gimeno RM, Rincón-León F 2004: Performance of response surface and Davey model prediction of Staphylococcus aureus growth parameters under different experimental conditions. J Food Protect 67: 1138-1145 